Article

\title{
Production, Characterization, and Antioxidant Activity of Fucoxanthin from the Marine Diatom Odontella aurita
}

\author{
Song Xia ${ }^{1}$, Ke Wang ${ }^{1}$, Linglin Wan ${ }^{1}$, Aifen $\mathrm{Li}^{1}$, Qiang $\mathrm{Hu}^{2, *}$ and Chengwu Zhang ${ }^{1, *}$ \\ 1 Institute of Hydrobiology, Jinan University, Guangzhou 510632, China; \\ E-Mails: xiasongsummer212@163.com (S.X); 476443371@qq.com (K.W.); \\ linglinwan@jnu.edu.cn (L.W.); tiger@jnu.edu.cn (A.L.) \\ 2 Laboratory for Algae Research and Biotechnology, College of Technology and Innovation, Arizona \\ State University, 7001 E. Williams Field Road, Mesa, AZ 85212, USA \\ * Authors to whom correspondence should be addressed; E-Mails: huqiang@asu.edu (Q.H.); \\ tzhangcw@jnu.edu.cn (C.Z.); Tel.: +1-480-727-1484 (Q.H.); Fax: +1-480-727-1275 (Q.H.); \\ Tel./Fax: +86-208-522-4366 (C.Z.).
}

Received: 23 April 2013; in revised form: 7 June 2013 / Accepted: 8 July 2013 /

Published: 23 July 2013

\begin{abstract}
The production, characterization, and antioxidant capacity of the carotenoid fucoxanthin from the marine diatom Odontella aurita were investigated. The results showed that low light and nitrogen-replete culture medium enhanced the biosynthesis of fucoxanthin. The maximum biomass concentration of $6.36 \mathrm{~g} \mathrm{~L}^{-1}$ and maximum fucoxanthin concentration of $18.47 \mathrm{mg} \mathrm{g}^{-1}$ were obtained in cultures grown in a bubble column photobioreactor ( $\varnothing 3.0 \mathrm{~cm}$ inner diameter), resulting in a fucoxanthin volumetric productivity of $7.96 \mathrm{mg} \mathrm{L}^{-1}$ day $^{-1}$. A slight reduction in biomass production was observed in the scaling up of $O$. aurita culture in a flat plate photobioreactor, yet yielded a comparable fucoxanthin volumetric productivity. A rapid method was developed for extraction and purification of fucoxanthin. The purified fucoxanthin was identified as all-trans-fucoxanthin, which exhibited strong antioxidant properties, with the effective concentration for 50\% scavenging $\left(\mathrm{EC}_{50}\right)$ of 1,1-dihpenyl-2-picrylhydrazyl (DPPH) radical and 2,2'-Azino-bis(3-ethylbenzthiazoline-6-sulfonic acid (ABTS) radical being 0.14 and $0.03 \mathrm{mg} \mathrm{mL}^{-1}$, respectively. Our results suggested that $O$. aurita can be a natural source of fucoxanthin for human health and nutrition.
\end{abstract}

Keywords: microalgae; Odontella aurita; fucoxanthin; photobioreactor; antioxidant 


\section{Introduction}

Fucoxanthin is a major carotenoid in seaweeds and diatoms. This pigment forms, together with chlorophyll (Chl) $a, \mathrm{Chl} c$ and an apoprotein, a major light-harvesting fucoxanthin, chlorophyll $a / c$ complex, which transfers light energy to chlorophyll $a$ of the photosynthetic reaction centers for photosynthesis [1]. Fucoxanthin has an allenic bond, a conjugated carbonyl, a 5,6-monoepoxide and an acetyl groups that contribute to a unique structure of the molecule. It has been reported that this carotenoid exhibits strong antioxidant, anti-inflammatory, anti-obesity, antidiabetic, anticancer, and antihypertensive activities [2,3]. Fucoxanthin can also be used as an animal feed additive in poultry and aquaculture industries [4].

Owing to its broad application potential, commercial production of fucoxanthin from algae has been explored. Several studies were conducted to extract fucoxanthin from brown macroalgae, such as Laminaria japonica, Eisenia bicyclis, and Undaria pinnatifida [5,6]. Because these macroalgae are traditional foods in South-East Asia and some European countries, and they contain very low concentrations (e.g., 0.02 to $0.58 \mathrm{mg} \mathrm{g}^{-1}$ fresh weight) of fucoxanthin, the production of fucoxanthin from brown macroalgae is not commercially feasible [7]. Therefore, searching for alternative sources of fucoxanthin is necessary.

Some microalgae can produce large amounts of specific carotenoids, such as $\beta$-carotene in Dunaliella salina, astaxanthin in Haematococcus pluvialis, and lutein in Scenedesmus almeriensis and Muriellopsis sp. [8]. With an estimated 100,000 species, fucoxanthin-containing diatoms constitute a large group of fresh water and marine microalgae, accounting for about $40 \%$ of the marine primary productivity and contributing to as high as $20 \%-25 \%$ of the global net primary production [9]. Despite their abundance and diversity in the aquatic environment, a few species have commercially been exploited for fucoxanthin production [10].

Odontella aurita is a bobbin-like unicell, normally ranging from 15 to $30 \mu \mathrm{m}$ in length. The microalga contains high concentrations (28\% of total fatty acids) of the long chain polyunsaturated fatty acid eicosapentaenoic acid (EPA, 20:503) and has been tested for mass culture in open ponds [11]. In this study, we determined that $O$. aurita can accumulate high concentrations of fucoxanthin ( $>20 \mathrm{mg} \mathrm{g}^{-1}$ of dry weight). The effects of nitrogen concentration and light intensity on fucoxanthin production in this diatom were investigated. The commercial potential of fucoxanthin production from $O$. aurita was also assessed in a pilot-scale flat plate photobioreactor. A rapid extraction procedure was developed for extraction of fucoxanthin, which was further purified by a silica gel-based preparation high performance liquid chromatography (prep-HPLC). The structural characteristics and antioxidant activity of highly purified fucoxanthin were investigated.

\section{Results and Discussion}

\subsection{Growth Kinetics and Fucoxanthin Production in the Bubble Column Photobioreactor}

Nitrogen concentration and incident light intensity are two major factors affecting growth and pigment biosynthesis of microalgae [12-14]. A common trend of cellular response to stress conditions, such as high light and nitrogen depletion, appears to increase secondary carotenoids (e.g., $\beta$-carotene, astaxanthin, lutein), which serve as photoprotective agents [14]. Harker et al. [15] reported that the 
astaxanthin content increased when $H$. pluvialis was cultivated in media deficient in nitrogen. When exposed to high light intensity, D. salina accumulated large quantities of $\beta$-carotene [16].

To evaluate the potential of fucoxanthin production in $O$. aurita, growth experiments were conducted in the $\varnothing 3 \mathrm{~cm}$ of bubble column photobioreactor with a nitrogen-replete $(18 \mathrm{mM})$ and a nitrogen-limited $(6 \mathrm{mM})$ culture media. The cultures were subjected to a low $\left(100 \mu \mathrm{mol}\right.$ photons $\left.\mathrm{m}^{-2} \mathrm{~s}^{-1}\right)$ and a high $\left(300 \mu \mathrm{mol}\right.$ photons $\left.\mathrm{m}^{-2} \mathrm{~s}^{-1}\right)$ light intensities. At the low light, $O$. aurita exhibited nearly identical growth with the two different concentrations of nitrogen, and the maximum biomass concentration ( $c a .4 \mathrm{~g} \mathrm{~L}^{-1}$ ) of the cultures occurred on day 10 (Figure 1A). At the high light, more rapid growth occurred in the cultures containing the higher nitrogen concentration and the maximum biomass concentration of $6.36 \mathrm{~g} \mathrm{~L}^{-1}$ was obtained on day 10 , which was about $50 \%$ higher than that (4.24 $\mathrm{g} \mathrm{L}^{-1}$ ) in the low nitrogen cultures (Figure 1B).

Figure 1. The growth profile $(\mathbf{A}, \mathbf{B})$ and fucoxanthin concentration $(\mathbf{C}, \mathbf{D})$ of $O$. aurita cultivated in the bubble column photobioreactor under $150(\mathbf{A}, \mathbf{C})$ and $300(\mathbf{B}, \mathbf{D}) \mu \mathrm{mol}$ photons $\mathrm{m}^{-2} \mathrm{~s}^{-1}$ light intensity with replete $(18 \mathrm{mM})$ and deficient $(6 \mathrm{mM})$ nitrate supply. Each value is expressed as mean $\pm \mathrm{SD}(n=3)$.
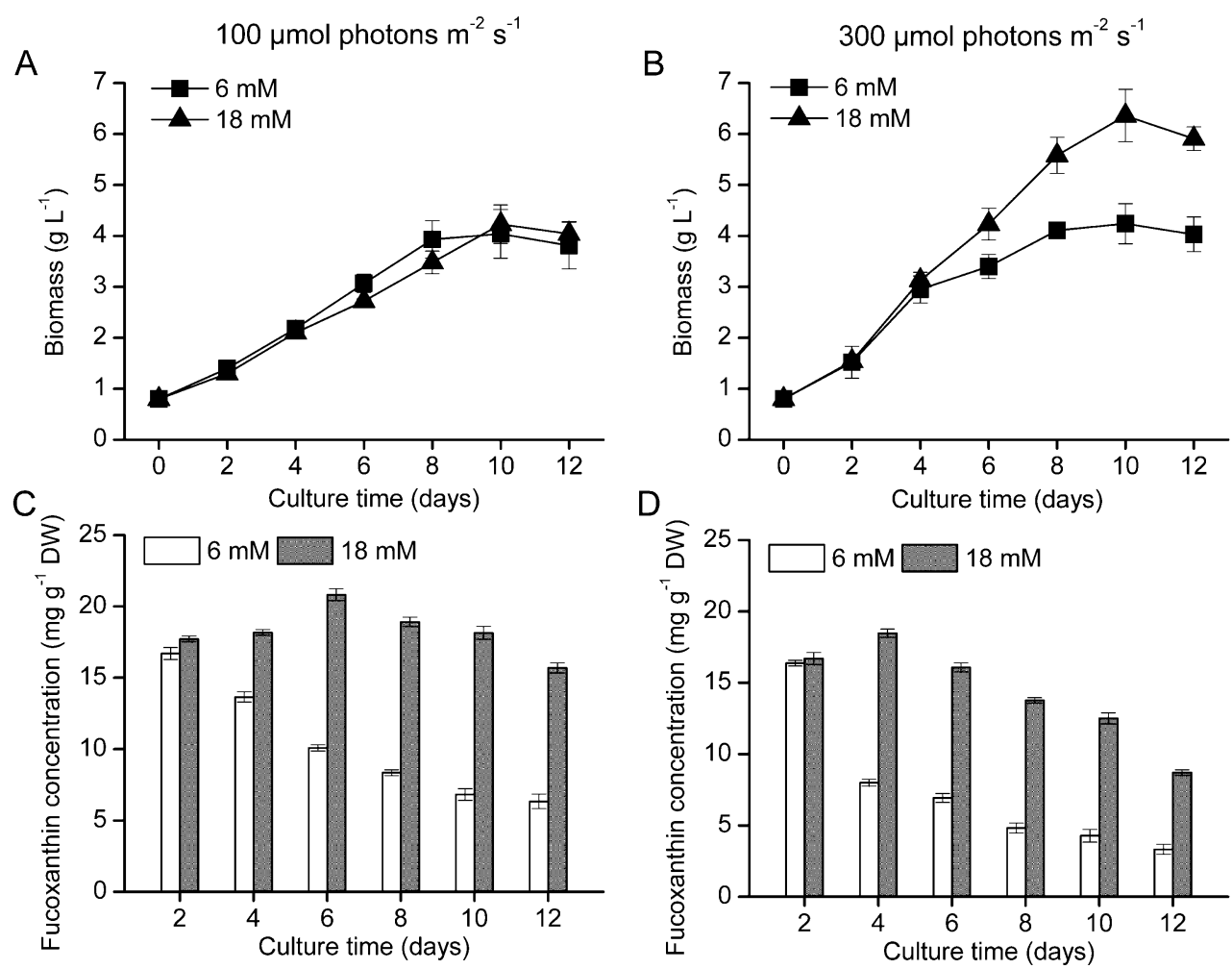

At the low light, the fucoxanthin concentration in the low nitrogen cultures decreased from $16.71 \mathrm{mg} \mathrm{g}^{-1}$ to $6.34 \mathrm{mg} \mathrm{g}^{-1}$ during a 12-day cultivation. In the high nitrogen cultures, the pigment increased to $20.83 \mathrm{mg} \mathrm{g}^{-1}$ on day six and then gradually decreased to $15.70 \mathrm{mg} \mathrm{g}^{-1}$ at the end of the 12-day culture period (Figure 1C). At the high light, the changes in fucoxanthin concentration in both the low and high nitrogen cultures followed essentially the same trends of their counterparts under the low light with a slight difference being that the final pigment concentrations in the low and high nitrogen cultures were about half of that occurred in their counter parts under the low light (Figure 1D). 
Carreto and Catoggio found that the cellular fucoxanthin and chlorophyll contents in Phaeodactylum tricornutum decreased with the age of culture, accompanied by a slight increase in the diadinoxanthin content [17]. Unlike secondary carotenoids (e.g., $\beta$-carotene, astaxanthin), which play a role in preventing excess light energy from reaching the photosynthetic machinery, fucoxanthin act as a primary carotenoid, whereby transferring light energy to the photosynthetic reaction centers for photosynthesis [14]. Under stress conditions, changes in the organization of the photosynthetic apparatus (e.g., chloroplast fragmentation, degradation of thylakoid membrane) occur, chlorophyll $a$ and other pigments involved in photosynthesis decrease, while the secondary carotenoids increase. These variations in pigment content might be as a quotient between photosynthetically active pigments and other functional pigments.

The fucoxanthin volumetric concentration and productivity of the microalga cultivated under the different conditions was compared (Table 1). The highest fucoxanthin volumetric concentration and productivity in the low nitrate supply and low light intensity cultures were $27.11 \mathrm{mg} \mathrm{L}$ and $2.71 \mathrm{mg} \mathrm{L}^{-1}$ day $^{-1}$, respectively, which increased to $76.73 \mathrm{mg} \mathrm{L}^{-1}$ and $7.67 \mathrm{mg} \mathrm{L}^{-1}$ day $^{-1}$, respectively in the nitrate-replete cultures. However, further increasing light intensity from 100 to $300 \mu \mathrm{mol}$ photons $\mathrm{m}^{-2} \mathrm{~s}^{-1}$ led to a considerable decrease of the fucoxanthin concentration in the cells, the biomass concentration had a significant enhancement under the high light intensity. The maximum fucoxanthin volumetric concentration of $79.56 \mathrm{mg} \mathrm{L}^{-1}$ was obtained with replete nitrate supply and high light intensity, resulting in a record high fucoxanthin volumetric productivity of $7.96 \mathrm{mg} \mathrm{L}^{-1}$ day $^{-1}$.

Table 1. The fucoxanthin concentration, volumetric concentration and volumetric productivity of $O$. aurita cultivated in bubble column photobioreactors with replete $(18 \mathrm{mM})$ and deficient $(6 \mathrm{mM})$ nitrate supply under low $\left(100 \mu \mathrm{mol}\right.$ photons $\left.\mathrm{m}^{-2} \mathrm{~s}^{-1}\right)$ and high $\left(300 \mu \mathrm{mol}\right.$ photons $\left.\mathrm{m}^{-2} \mathrm{~s}^{-1}\right)$ light irradiation on day 10 .

\begin{tabular}{|c|c|c|c|c|}
\hline \multirow[b]{2}{*}{$\begin{array}{c}\text { Light intensity } \\
\left(\mu \mathrm{mol} \text { photons } \mathrm{m}^{-2} \mathbf{s}^{-1}\right)\end{array}$} & \multirow[b]{2}{*}{$\begin{array}{l}\text { Nitrate concentration } \\
(\mathrm{mM})\end{array}$} & \multicolumn{3}{|c|}{ Fucoxanthin } \\
\hline & & $\begin{array}{c}\text { Concentration } \\
\left(\mathrm{mg} \mathrm{g}^{-1}\right)\end{array}$ & $\begin{array}{c}\text { Volumetric concentration } \\
\qquad\left(\mathrm{mg} \mathrm{L}^{-1}\right)\end{array}$ & $\begin{array}{c}\text { Volumetric productivity } \\
\qquad\left(\mathrm{mg} \mathrm{L}^{-1} \text { day }^{-1}\right)\end{array}$ \\
\hline \multirow{2}{*}{100} & 6 & 6.71 & 27.11 & 2.71 \\
\hline & 18 & 18.14 & 76.73 & 7.67 \\
\hline \multirow{2}{*}{300} & 6 & 4.28 & 18.15 & 1.82 \\
\hline & 18 & 12.51 & 79.56 & 7.96 \\
\hline
\end{tabular}

\subsection{Mass Production Potential in the Pilot-Scale Flat Plate Photobioreactor}

To assess culture system scale-up feasibility, $O$. aurita was cultivated in a pilot-scale flat plate photobioreactor with replete $(18 \mathrm{mM})$ nitrate supply under a high light intensity of $300 \mu \mathrm{mol}$ photons $\mathrm{m}^{-2} \mathrm{~s}^{-1}$. Results showed that the light path exerted a strong influence on growth of this microalga. The maximum biomass concentration of $3.53 \mathrm{~g} \mathrm{~L}^{-1}$ was obtained in a $3 \mathrm{~cm}$ light-path photobioreactor ( $75 \mathrm{~L}$ volume) on day 10 , which decreased to $2.14 \mathrm{~g} \mathrm{~L}^{-1}$ when the reactor light path increased to $6 \mathrm{~cm}$ (150 L volume) (Figure 2A). As indicated in Figure 2B, litter difference in fucoxanthin concentration was observed in the two light path photobioreactors, and the fucoxanthin concentration in the dry biomass was stabilized at a high level of 18.01 21.67 $\mathrm{mg} \mathrm{g}^{-1}$. 
Figure 2. The growth profile (A) and fucoxanthin concentration (B) of $O$. aurita cultivated in the $3 \mathrm{~cm}(75 \mathrm{~L})$ and $6 \mathrm{~cm}(150 \mathrm{~L})$ flat plate photobioreactor under $300 \mu \mathrm{mol}$ photons $\mathrm{m}^{-2} \mathrm{~s}^{-1}$ light intensity with replete $(18 \mathrm{mM})$ nitrate supply. Each value is expressed as mean $\pm \operatorname{SD}(n=3)$.
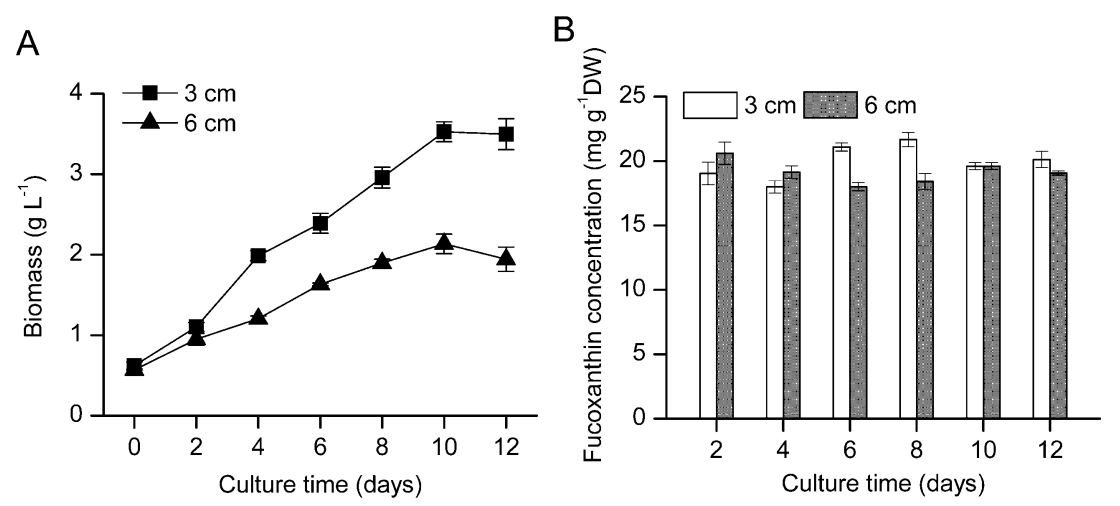

As a result, the fucoxanthin volumetric productivity of the $3 \mathrm{~cm}$ light path photobioreactor was greater than that obtained in the $6 \mathrm{~cm}$ light path one (Table 2). The fucoxanthin volumetric productivity in $3 \mathrm{~cm}$ light-path photobioreactor was comparable to that obtained in the smaller volume bubble column bioreactor, demonstrating the promising feasibility of $O$. aurita culture at scale.

Table 2. The fucoxanthin concentration, volumetric concentration and volumetric productivity of $O$. aurita cultivated in $3 \mathrm{~cm}$ and $6 \mathrm{~cm}$ flat plate photobioreactors under $300 \mu \mathrm{mol}$ photons $\mathrm{m}^{-2} \mathrm{~s}^{-1}$ light irradiation on day 10 .

\begin{tabular}{|c|c|c|c|}
\hline \multirow[b]{2}{*}{$\begin{array}{l}\text { Light path } \\
(\mathbf{c m}) \\
\end{array}$} & \multicolumn{3}{|c|}{ Fucoxanthin } \\
\hline & $\begin{array}{c}\text { Concentration } \\
\left(\mathrm{mg} \mathrm{g}^{-1}\right) \\
\end{array}$ & $\begin{array}{c}\text { Volumetric concentration } \\
\left(\mathrm{mg} \mathrm{L}^{-1}\right)\end{array}$ & $\begin{array}{c}\text { Volumetric productivity } \\
\left(\mathrm{mg} \mathrm{L}^{-1} \text { day }^{-1}\right)\end{array}$ \\
\hline 3 & 19.59 & 69.15 & 6.92 \\
\hline 6 & 19.61 & 41.97 & 4.20 \\
\hline
\end{tabular}

Microalgae are considered as alternative sources for various bioactive compounds. Several carotenoids, such as astaxanthin, lutein, and $\beta$-carotene, have been commercially produced from microalgae. For example, the chlorophycean microalga Muriellopsis sp. has a high lutein volumetric concentration of $c a .35 \mathrm{mg} \mathrm{L}^{-1}$ [18]. Commercial production of natural $\beta$-carotene was obtained by mass cultivation of the microalga $D$. salina obtained a high $\beta$-carotene volumetric concentration almost of $150 \mathrm{mg} \mathrm{L}^{-1}$ [19]. Natural astaxanthin produced by $H$. pluvialis has applications in the aquaculture and nutraceutical markets [20]. Fucoxanthin is a major carotenoid present in brown seaweeds and diatoms, and is very effective in chemoprevention of cancer in animal studies [21]. Most of these studies were conducted with fucoxanthin isolated from macroalgae, and the fucoxanthin concentration from these macroalgae ranged from 0.02 to $0.58 \mathrm{mg} \mathrm{g}^{-1}$ in fresh samples and 0.01 to $1.01 \mathrm{mg} \mathrm{g}^{-1}$ in dried samples (Table 3). In contrast, the reported fucoxanthin concentration in microalgae ranges from 2.24 to $18.23 \mathrm{mg} \mathrm{g}^{-1}$, which is in one to three orders of magnitude greater than that found in macroalgae, indicative of the great potential of diatoms as a promising source of fucoxanthin for various commercial applications. The fucoxanthin concentration of $3.33-21.67 \mathrm{mg} \mathrm{g}^{-1}$ and the 
volumetric concentration of $18.15-79.56 \mathrm{mg} \mathrm{L}^{-1}$ obtained in the present study have set the records for algae-based fucoxanthin production.

Table 3. The fucoxanthin concentrations in the samples of different macroalgae and microalgae ${ }^{1}$.

\begin{tabular}{|c|c|c|c|c|}
\hline & Species & Fresh or dried & $\begin{array}{c}\text { Fucoxanthin concentration } \\
\qquad\left(\mathrm{mg} \mathrm{g}^{-1}\right)\end{array}$ & References \\
\hline \multirow{13}{*}{ Macroalgae } & Eisenia bicyclis & Fresh & 0.26 & {$[7]^{2}$} \\
\hline & Hizikia fusiformis & Fresh & 0.02 & {$[5]^{2}$} \\
\hline & Laminaria japonica & Fresh & 0.19 & {$[5]^{2}$} \\
\hline & Laminaria japonica & Fresh & 0.03 & {$[22]^{2}$} \\
\hline & Petalonia binghamiae & Fresh & $0.43-0.58$ & {$[23]^{3}$} \\
\hline & Scytosiphon lomentaria & Fresh & $0.24-0.56$ & {$[23]^{3}$} \\
\hline & Sargassum fusiforme & Dried & 0.01 & {$[22]^{2}$} \\
\hline & Sargassum binderib & Dried & 0.73 & {$[24]^{2}$} \\
\hline & Sargassum duplicatum & Dried & 1.01 & {$[24]^{2}$} \\
\hline & Sargassum plagyophyllum & Dried & 0.71 & {$[25]^{2}$} \\
\hline & Turbinaria turbinata & Dried & 0.59 & {$[25]^{2}$} \\
\hline & Undaria pinnatifida & Dried & 0.73 & {$[22]^{2}$} \\
\hline & Undaria pinnatifida & Fresh & 0.11 & {$[5]^{2}$} \\
\hline \multirow{8}{*}{ Microalgae } & Chaetoceros gracilis & Dried & 2.24 & {$[26]^{2}$} \\
\hline & Cylindrotheca closterium & Dried & 5.23 & {$[27]^{2}$} \\
\hline & Isochrysis aff. Galbana & Dried & 18.23 & {$[26]^{2}$} \\
\hline & Isochrysis galbana & Dried & 6.04 & {$[26]^{2}$} \\
\hline & Phaeodactylum tricornutum & Dried & 8.55 & {$[26]^{2}$} \\
\hline & Phaeodactylum tricornutum & Dried & $15.42-16.51$ & {$[7]^{2}$} \\
\hline & Nitzschia sp. & Dried & 4.92 & {$[26]^{2}$} \\
\hline & Odontella aurita & Dried & 21.67 & In this study \\
\hline
\end{tabular}

\footnotetext{
${ }^{1}$ Fucoxanthin concentration in algal samples were expressed as $\mathrm{mg} \mathrm{g}^{-1}$ dry (or fresh) weight of algal samples, unless special statement, fucoxanthin concentration represented all-trans-fucoxanthin concentration; ${ }^{2}$ The fucoxanthin concentration was quantified by HPLC using a standard curve with purified fucoxanthin or standard chemical; ${ }^{3}$ The fucoxanthin concentration was quantified by UV spectroscopy with E value $(1 \%, 1 \mathrm{~cm})$ of 1197 at $451 \mathrm{~nm}$ determined authentic fucoxanthin in $\mathrm{MeOH}-\mathrm{H}_{2} \mathrm{O}(9: 1)$.
}

\subsection{Optimization of Fucoxanthin Extraction Conditions}

The limited availability of natural fucoxanthin to date is not only due to the lack of sufficient supply of fucoxanthin-rich biomass feedstock, but also poor extraction efficiency of fucoxanthin from biomass [5,26]. In order to determine the optimal conditions for fucoxanthin extraction, five conventional solvents were tested to determine the most suitable solvent for extraction of fucoxanthin from $O$. aurita. The results showed that fucoxanthin extraction efficiency was highly dependent on the solvent type. Fucoxanthin concentration extracted with methanol $\left(16.18 \mathrm{mg} \mathrm{g}^{-1} \mathrm{DW}\right)$ was the highest among the five tested solvents, followed by ethanol (15.83 $\left.\mathrm{mg} \mathrm{g}^{-1} \mathrm{DW}\right)$ and acetone $\left(13.93 \mathrm{mg} \mathrm{g}^{-1} \mathrm{DW}\right)$. Petroleum ether and $n$-hexane did not effectively extract fucoxanthin from $O$. aurita (Figure 3A). The results were in accordance with findings reported by Kim et al. [7], who isolated fucoxanthin from the 
microalga $P$. tricornutum with different solvents, and the maximum fucoxanthin concentration (15.33 $\mathrm{mg} \mathrm{g}^{-1}$ ) was obtained with ethanol, while acetone extracted approximately one third of that with ethanol. Although ethanol had slightly lower extraction efficiency than methanol, it exerts lower toxicity, and thus was selected as the most suitable extraction solvent in further research.

Figure 3. The effect of (A) solvent type, (B) ethanol/dry biomass ratio (v/w), and (C) extraction temperature and time on the extracted fucoxanthin concentration from freeze-dried O. aurita. Each value is expressed as mean $\pm \operatorname{SD}(n=3)$.
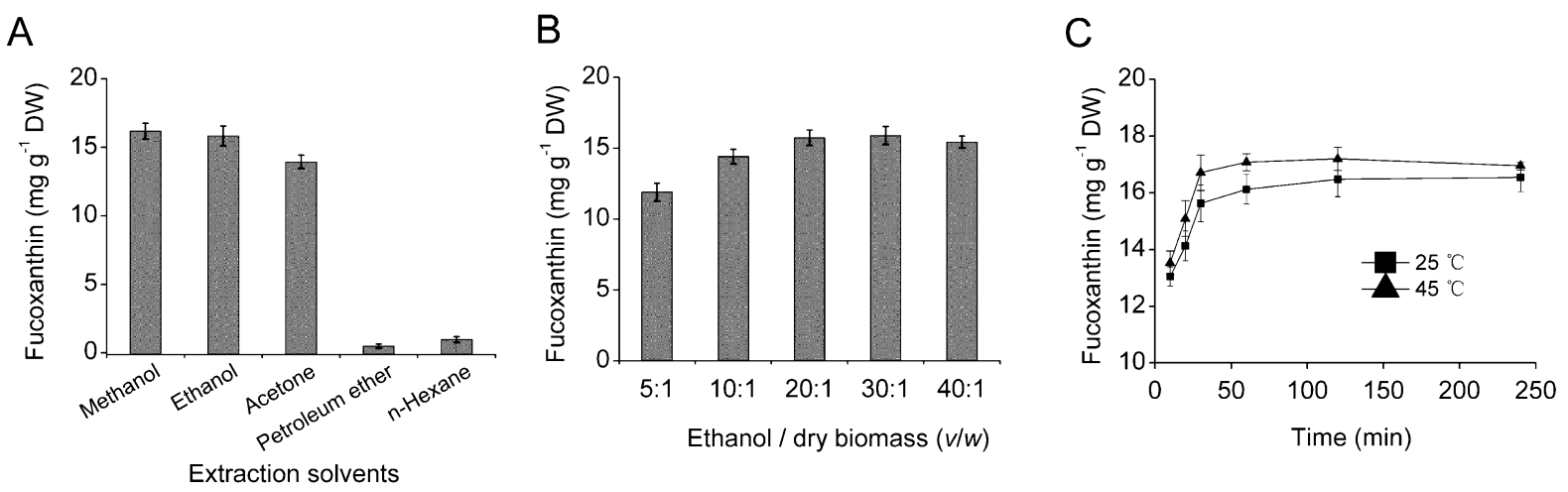

Selecting a proper ratio of solvent to dry algal biomass (v/w) is important, as it may affect the quantity and quality of fucoxanthin. As shown in Figure 3B, up to 20:1 ethanol/dry biomass, the fucoxanthin extraction efficiency increased remarkably (11.90-15.74 $\left.\mathrm{mg} \mathrm{g}^{-1} \mathrm{DW}\right)$ with increasing the ethanol to dry biomass ratio. When $O$. aurita dry biomass was treated with 30:1 ethanol/dry biomass, the fucoxanthin concentration increased slightly $\left(15.90 \mathrm{mg} \mathrm{g}^{-1} \mathrm{DW}\right)$, and further increasing of ethanol did not improve the fucoxanthin extraction efficiency. So, the ethanol/dry biomass ratio of 20:1 was sufficient for effective extraction of fucoxanthin from this microalga.

To assess the effect of temperature and extraction time on the fucoxanthin extraction efficiency, O. aurita was extracted at $25^{\circ} \mathrm{C}$ and $45^{\circ} \mathrm{C}$ with different extraction time, i.e., 10, 20, 30, 60, 120, and $240 \mathrm{~min}$. As shown in Figure 3C, increasing the extraction temperature from $25^{\circ} \mathrm{C}$ to $45^{\circ} \mathrm{C}$ increased the extracted fucoxanthin concentration from $16.12 \mathrm{mg} \mathrm{g}^{-1}$ to $17.20 \mathrm{mg} \mathrm{g}^{-1} \mathrm{DW}$, attributable likely to the elevated temperature enhanced solubilization of photosynthetic membranes and release of fucoxanthin from fucoxanthin-Chl $a, c$-protein complexes [5,7]. The extracted fucoxanthin concentration was also a function of extraction time. At $45{ }^{\circ} \mathrm{C}$, approximately $80 \%$ of fucoxanthin corresponding to $13.53 \mathrm{mg} \mathrm{g}^{-1}$ was extracted from algal biomass within the first $10 \mathrm{~min}$, and the maximum fucoxanthin concentration was obtained at approximately $60 \mathrm{~min}$.

\subsection{Purification and Identification of Fucoxanthin}

Fucoxanthin was extracted and purified following the procedure illustrated in Figure 4. Firstly, pigments were extracted from freeze-dried algal powder according to the optimized extraction conditions. The pigment composition of crude extracts was analyzed by HPLC and the results showed that fucoxanthin, cis-fucoxanthin, diadinoxanthin, diatoxanthin, and $\beta$-carotene were the major carotenoids in this species, accompanied by chlorophyll $a, c$ as its major chlorophyll pigments. The results were in accordance with the pigment profile previously reported in other diatoms. Stauber and 
Jeffrey analyzed the photosynthetic pigments of 51 species of marine diatoms, and found that all species contained chlorophyll $a$ and $c_{2}$ and $\beta$-carotene, fucoxanthin, diatoxanthin and diadinoxanthin [28].

Figure 4. Isolation and purification fucoxanthin from crude pigments extraction of $O$. aurita through silica gel column chromatography and preparation high performance liquid chromatography (prep-HPLC). All fractions were analyzed by HPLC for qualitative.

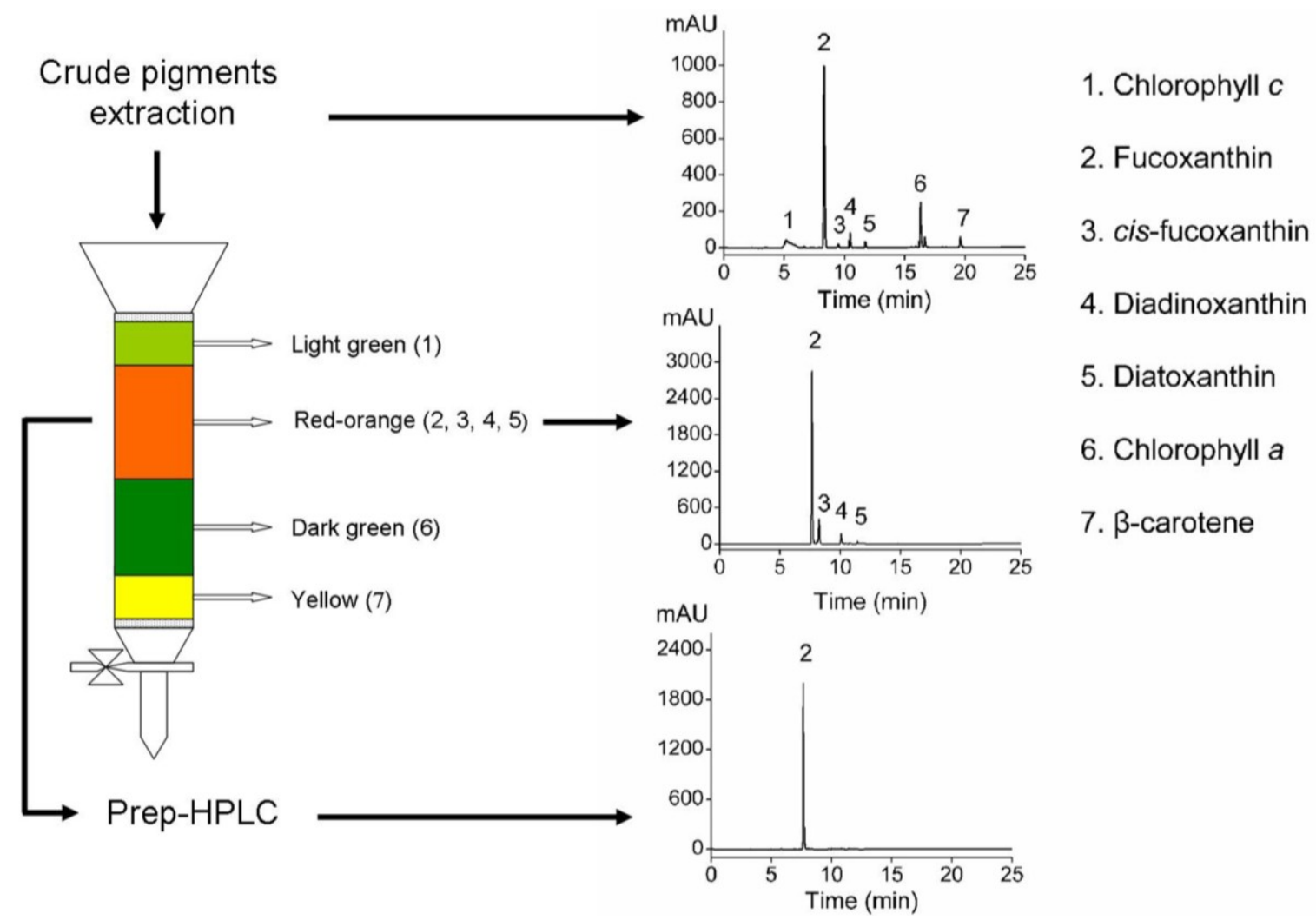

The crude pigment extracts were subject to open silica gel column chromatography with $n$-hexane/acetone ( $6: 4$ solution; $\mathrm{v} / \mathrm{v})$ being the eluting solvent system, and all fractions were analyzed by HPLC. An orange-red colored fucoxanthin-rich fraction, which consisted of fucoxanthin, cis-fucoxanthin, diadinoxanthin, and diatoxanthin, was separated by the column. The purity of fucoxanthin in the mixture was identified as high as $86.7 \%$. Further purification of fucoxanthin was carried out by a prep-HPLC, and pure fucoxanthin was collected. The purity of the fucoxanthin was $>97 \%$ as determined by HPLC.

The purified fucoxanthin was analyzed by LC-MS and NMR. The molecular mass spectrum corresponding to the molecular weight of fucoxanthin was identified based on the fragment pattern at $m / z 659.8$ and 681.9 corresponding to $[\mathrm{M}+\mathrm{H}]^{+}$and $[\mathrm{M}+\mathrm{Na}]^{+}$, respectively (Figure 5A). The purified fucoxanthin showing the same retention time and UV-visible spectrum ( $\lambda_{\max }$ at $448 \mathrm{~nm}$ ) with the fucoxanthin standard confirmed the molecule identification of the pigment (Figure 5B). The purified fucoxanthin was subjected to NMR spectroscopy for its structural determination (Table 3). The complete assignments of the ${ }^{1} \mathrm{H}$ and ${ }^{13} \mathrm{C}$ NMR spectra of fucoxanthin revealed the signals assignable to polyene containing acetyl, conjugated ketone, olefinic methyl, two quaternary germinal oxygen methyls, two quaternary germinal dimethyls, and allene groups. The NMR data agreed well with the 
findings from the diatom $P$. tricornutum and haptophyte Isochrysis aff. galbana [7,29], suggesting that fucoxanthin is major in a all-trans form in O. aurita (Figure 5C).

Figure 5. Identification of purified fucoxanthin from $O$. aurita. (A) The mass fragments; (B) UV-visible spectrum; (C) chemical structure of all-trans fucoxanthin.
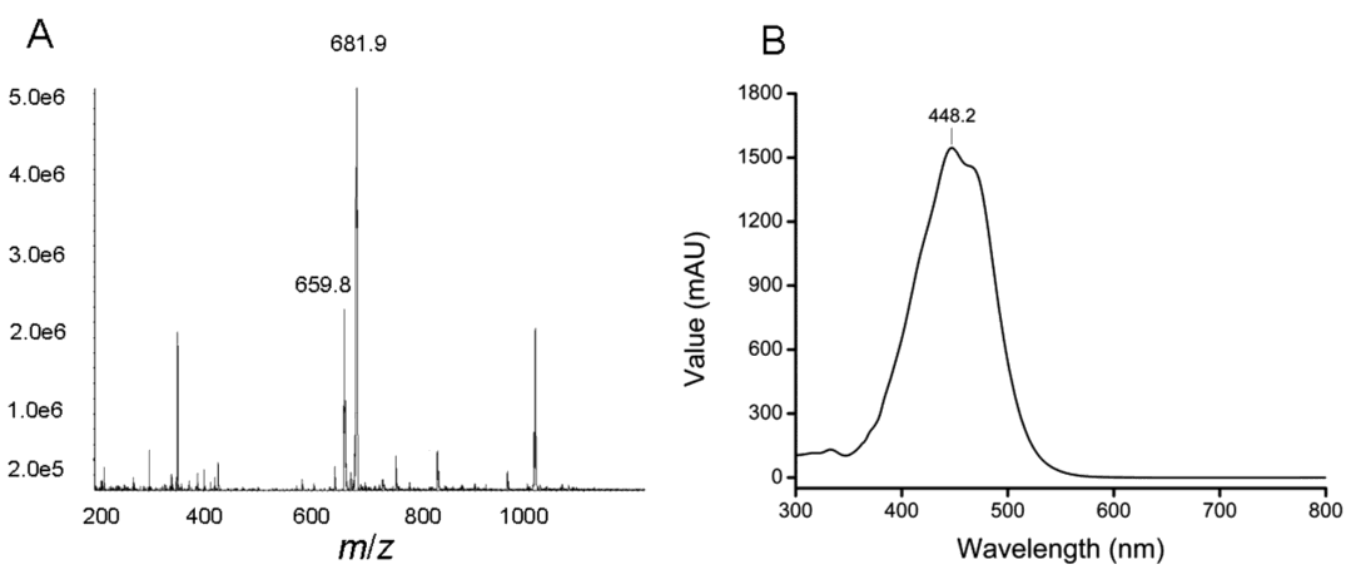

C

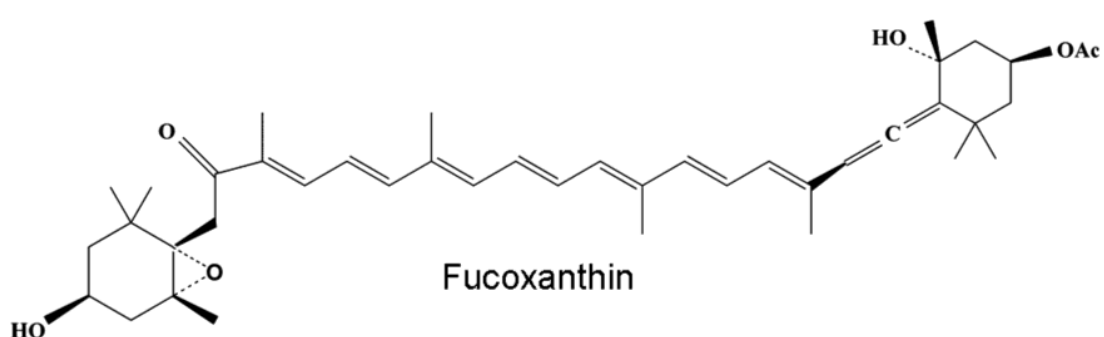

\subsection{Antioxidant Activity}

Reactive oxygen species (ROS) formed under photooxidation stress can react with macromolecules like lipids and proteins leading to cellular damage. Antioxidants are substances that have the ability to reduce ROS and prevent macromolecules from oxidation [30]. 1,1-Dihpenyl-2-picrylhydrazyl (DPPH) and 2,2'-Azino-bis(3-ethylbenzthiazoline-6-sulfonic acid (ABTS) radicals were stable radical sources for evaluation of free radical-scavenging ability of various compounds [31].

To evaluate the antioxidant capacity of fucoxanthin purificated from $O$. aurita, DPPH and ABTS-based radical scavenging and reducing power assays were carried out. Ascorbic acid, a standard antioxidant, was used as a positive control (Figure 6). As the fucoxanthin concentration increased from $0.1 \mathrm{mg} \mathrm{mL}^{-1}$ to $1 \mathrm{mg} \mathrm{mL}^{-1}$, the reducing power of fucoxanthin increased in a concentration-dependent manner, thought the reducing capacity was somewhat lower than that of ascorbic acid (Figure 6A). The similar scavenging activity pattern was observed in the DPPH assay. The DPPH radical scavenging activity was linearly dependent on the fucoxanthin concentration; the effective concentration for $50 \%$ scavenging $\left(\mathrm{EC}_{50}\right)$ was $0.14 \mathrm{mg} \mathrm{mL}^{-1}$ (Figure $6 \mathrm{~B}$ ). Fucoxanthin was an excellent scavenging agent to ABTS radicals. The ABTS radical scavenging rate increased in a concentration-dependent manner when fucoxanthin concentration increased from $0.02 \mathrm{mg} \mathrm{mL}^{-1}$ to $0.08 \mathrm{mg} \mathrm{mL}^{-1}$, and the $\mathrm{EC}_{50}$ for ABTS radical was almost $0.03 \mathrm{mg} \mathrm{mL}^{-1}$. A plateau occurred at $0.2 \mathrm{mg} \mathrm{mL}^{-1}$ with a scavenging rate of $90.3 \%$. 
Figure 6. Antioxidant assays for the purified fucoxanthin from O. aurita. (A) Reducing power; (B) scavenging of DPPH radical; (C) scavenging of ABTS radical. Values were representative of three independent experiments.
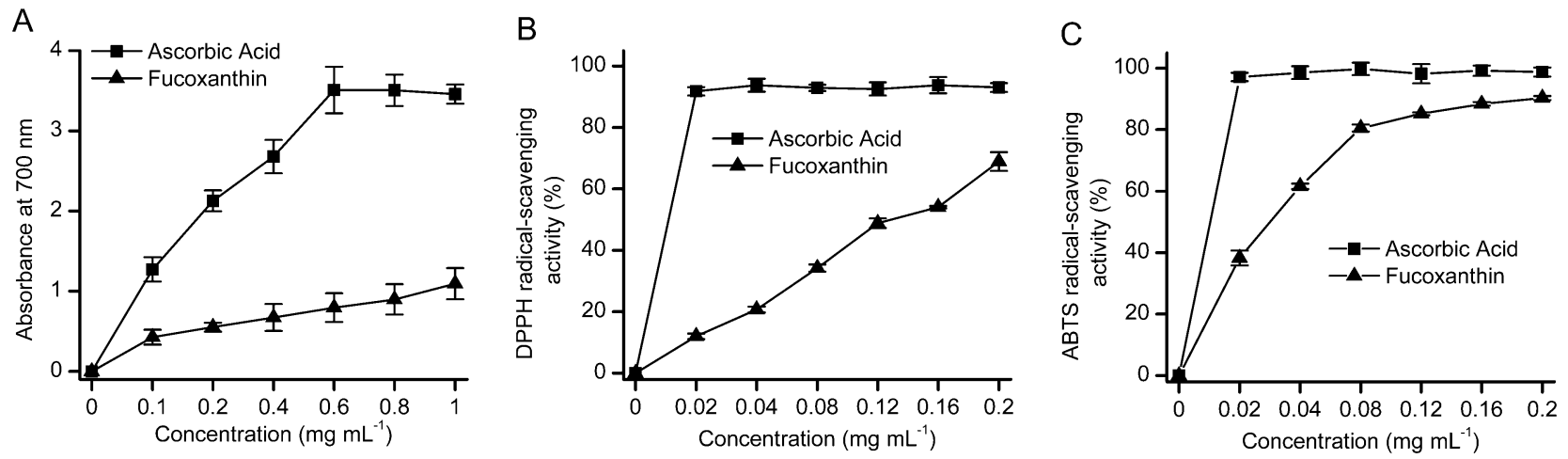

It was reported that the extracts of brown seaweed Cystoseira hakodatensis exhibited a strong DPPH radical scavenging activity, due largely to the presence of fucoxanthin [32]. Sachindra et al. [33] assessed the radical scavenging abilities of macroalgae-derived fucoxanthin and its two metabolites - fuxoxanthinol and halocynthiaxanthin - against DPPH, ABTS, hydroxyl radical, and superoxide radical, and suggested that fucoxanthin and fucoxanthinol exhibited higher than or similar activities to $\alpha$-tocopherol.

\section{Experimental Section}

\subsection{Organism and Culture Conditions}

O. aurita was obtained from the Scandinavian Culture Collection of Algae and Protozoa at the University of Copenhagen and maintained in a modified L1 medium prepared from artificial seawater [34].

Culture experiments were conducted with three types of photobioreactors: $\varnothing 3 \times 60 \mathrm{~cm}$ bubble columns with a working volume of $320 \mathrm{~mL}$ and a flat plate photobioreactor measuring $3 \mathrm{~cm}$ depth, $240 \mathrm{~cm}$ length $\times 120 \mathrm{~cm}$ height with a working volume of $75 \mathrm{~L}$, and a similar photobioreactor measuring $6 \mathrm{~cm}$ depth, $240 \mathrm{~cm}$ length $\times 120 \mathrm{~cm}$ height, with a working volume of $150 \mathrm{~L}$. Cultures were carried out indoor at $25 \pm 2{ }^{\circ} \mathrm{C}$ and aerated with compressed air containing $1 \% \mathrm{CO}_{2}$. Continuous illumination was provided by a bank of cool white fluorescent lamps from one side of photobioreactor at an intensity of 100 or $300 \mu \mathrm{mol}$ photons $\mathrm{m}^{-2} \mathrm{~s}^{-1}$. Light intensity was measured on the outer surface of photobioreactor with a dual radiation meter (Apogee DRM-FQ, Logan, UT, USA).

\subsection{Biomass Measurement}

Ten milliliters $(10 \mathrm{~mL})$ culture was filtered through a pre-weighed GF/B filter paper and washed with ammonium formate. The filter paper with algal sample was dried in an oven at $105{ }^{\circ} \mathrm{C}$ overnight, and then weighed. The dry weight (DW) of sample was calculated by the difference in weights of the filter paper with and without algal sample. 


\subsection{Pigment Extraction and Analysis}

Ten milligrams $(10 \mathrm{mg})$ freeze-dried microalgal powder was extracted with $5 \mathrm{~mL}$ ethanol in conical centrifugation tube with a magnetic stirrer for $2 \mathrm{~h}$ in the dark. After extraction, the mixture was centrifuged for $5 \mathrm{~min}$ at $3500 \mathrm{rpm}$ and supernatant was collected for pigments analysis by HPLC. Two hundred milligrams $(200 \mathrm{mg}$ ) freeze-dried microalgal powder cultivated in the $3 \mathrm{~cm}$ flat plate photobioreactor on day 12 was used for the optimization of extraction conditions. Various solvents (methanol, ethanol, acetone, petroleum ether, and $n$-hexane), solvent volume to dry biomass weight ratio $(5: 1,10: 1,20: 1,30: 1$, and $40: 1)$, extraction temperature $\left(25^{\circ} \mathrm{C}\right.$ and $\left.45^{\circ} \mathrm{C}\right)$ and time $(10,20,30$, 60,120 , and $240 \mathrm{~min}$ ) were tested to determine the optimal conditions for fucoxanthin extraction. Every procedure was performed under dim light to prevent pigment degradation or photooxidation. All experiments were performed independently in triplicate. Each pigment extraction was filtered through a $0.2 \mu \mathrm{m}$ Nylon membrane filter (Millipore, Billerica, MA, USA) before HPLC analysis.

\subsection{Purification of Fucoxanthin}

Based on the optimal extraction conditions developed above, $50 \mathrm{~g}$ freeze-dried microalgal powder produced from a 12-day culture of $O$. aurita in the $3 \mathrm{~cm}$ flat plate photobioreactor was extracted with $1 \mathrm{~L}$ ethanol at $45{ }^{\circ} \mathrm{C}$ for $1 \mathrm{~h}$. The extracts were filtered and then concentrated in a rotary evaporator (Büchi R-205V805, Flawil, Switzerland) under vacuum conditions at $45{ }^{\circ} \mathrm{C}$. The concentrated extracts were loaded onto a silica gel (200-300 mesh, Qingdao Haiyang Chemical Co., Ltd., Qingdao, China) packed into a glass column $(2 \times 30 \mathrm{~cm})$ and equilibrated with a mixture of $n$-hexane:acetone (6:4), then eluted with the same solvent. The orange-red fucoxanthin-containing fraction was collected and concentrated into a small volume. Further purification of fucoxanthin was carried out by prep-HPLC.

\subsection{HPLC and LC-MS Analysis}

Pigment analysis was performed on a Dionex model U-3000 HPLC (Dionex, Sunnyvale, CA, USA). A Kromasil $\mathrm{C}_{18}$ reverse phase column $(5 \mu \mathrm{m}$ particle size, $250 \times 4.6 \mathrm{~mm}$ ID, Dionex, Sunnyvale, CA, USA) coupled with a $\mathrm{C}_{18}$ guard column $(5 \mu \mathrm{m}$ particle size, $15 \times 4.6 \mathrm{~mm}$ ID) was used. The mobile phases and the elution program were adopted from our previous report [35]. A calibration curve $\left(10-200 \mu \mathrm{g} \mathrm{mL}^{-1}\right)$ was established for quantification of fucoxanthin by HPLC using a all-trans-fucoxanthin standard (Cayman Chemical, Ann Arbor, MI, USA). The amount of fucoxanthin was calculated from the peak area by the standard curve. Fucoxanthin concentration in the microalgal samples were expressed as $\mathrm{mg} \mathrm{g}^{-1}$ dry weight of samples. Purified fucoxanthin was analyzed with an Agilent 1100 module (Agilent Technologies, Wilmington, DE, USA), coupled with an API 4000 Q-TRAP MS system (Applied Biosystems, Foster City, CA, USA). The mobile phase and gradient conditions were the same as that for the HPLC analysis. The MS conditions were set as follows: positive ions in the range from $m / z 200-1000$ were measured. An ion source voltage of $5.5 \mathrm{kV}$, a cone voltage of $60 \mathrm{~V}$, a nebulizing gas of $30 \mathrm{psi}$, and a curtain gas of 10 psi were applied. 


\subsection{NMR Analysis}

Purified fucoxanthin (10 mg) from Prep-HPLC was dissolved in $1 \mathrm{~mL} \mathrm{CD}_{3} \mathrm{OD}$ and used for NMR spectroscopy. The ${ }^{1} \mathrm{H}$ and ${ }^{13} \mathrm{C}$ NMR signals were recorded on a Varian Inova $500 \mathrm{MHz}$ NMR system (Vernon Hills, IL, USA) with a carbon enhanced cold probe $\left({ }^{1} \mathrm{H}\right.$ with $500 \mathrm{MHz}$, ${ }^{13} \mathrm{C}$ with $126 \mathrm{MHz})$. Chemical shifts were adjusted with $\delta(\mathrm{ppm})$ referring to the solvents peaks $\delta_{\mathrm{H}} 3.31$ and $\delta_{\mathrm{C}} 49.2$ for $\mathrm{CD}_{3} \mathrm{OD}$. Data were processed with the MestReNova program and compared with data in the literature.

\subsection{Assay for Antioxidant Activity}

The reducing power of fucoxanthin was determined according to the method of Deng [36] with minor modification. Briefly, $1 \mathrm{~mL}$ ethanolic fucoxanthin solution $\left(0.1-1 \mathrm{mg} \mathrm{mL}^{-1}\right)$ was mixed with $0.2 \mathrm{~mL} 0.2 \mathrm{M}$ sodium phosphate buffer ( $\mathrm{pH} 6.6)$ and $1.5 \mathrm{~mL} 1 \%(\mathrm{w} / \mathrm{v})$ potassium ferricyanide. The mixture was incubated at $50{ }^{\circ} \mathrm{C}$ for $20 \mathrm{~min}$ under water bath. Then $1 \mathrm{~mL} 10 \%(\mathrm{w} / \mathrm{v})$ trichloroacetic acid was added. The resultant mixture was centrifuged for $10 \mathrm{~min}$ at $3500 \mathrm{rpm}$. Two milliliters $(2 \mathrm{~mL})$ supernatant was diluted with $3 \mathrm{~mL}$ distilled water and then mixed with $0.5 \mathrm{~mL} 0.3 \%(\mathrm{w} / \mathrm{v})$ ferric chloride. The absorbance was measured at $700 \mathrm{~nm}$ against a blank. Ascorbic acid was taken as a positive control. The increased absorbance indicates an increased reducing power.

The scavenging activity of DPPH radical was determined as describe by Sachindra et al. [33]. Briefly, $2 \mathrm{~mL}$ ethanolic fucoxanthin solution $\left(0.02-0.2 \mathrm{mg} \mathrm{mL}^{-1}\right)$ was mixed with $2 \mathrm{~mL} 0.16 \mathrm{mM}$ ethanolic solution of DPPH. The mixture was shaken vigorously and incubated for $30 \mathrm{~min}$ at room temperature in the dark. The absorbance was measured at $517 \mathrm{~nm}$. Ascorbic acid was taken as a positive control. The scavenging ability was calculated as: DPPH radical scavenging activity $(\%)=$ $\left[1-\left(A_{1}-A_{2}\right) / A_{0}\right] \times 100$, where $A_{0}$ is the absorbance in the lack of fucoxanthin (using distilled water instead of fucoxanthin), $A_{1}$ is the absorbance in the presence of fucoxanthin, and $A_{2}$ is the absorbance of ethanolic fucoxanthin solution (using ethanol instead of DPPH).

The scavenging activity of ABTS radical was measured as described by Osman [37] with minor modifications. The pre-formed ABTS free radicals were generated by reacting $7 \mathrm{mM}$ ABTS diammonium salt and $2.45 \mathrm{mM}$ potassium persulphate overnight at room temperature in the dark. The solution was diluted with $95 \%(\mathrm{v} / \mathrm{v})$ ethanol until the absorbance at $734 \mathrm{~nm}$ reaching $0.7 \pm 0.01$ units. Three milliliters $(3 \mathrm{~mL})$ diluted ABTS radical solution was added to $1 \mathrm{~mL}$ ethanolic fucoxanthin solution $\left(0.02-0.2 \mathrm{mg} \mathrm{mL}^{-1}\right)$. The mixture was incubated at $30{ }^{\circ} \mathrm{C}$ for $60 \mathrm{~min}$ in a water bath. The absorbance at $734 \mathrm{~nm}$ was measured. Ascorbic acid was taken as a positive control. The scavenging ability was calculated as: ABTS radical scavenging activity $(\%)=\left[\left(\mathrm{A}_{0}-\mathrm{A}\right) / \mathrm{A}_{0}\right] \times 100$, where $\mathrm{A}_{0}$ is the absorbance of the control reaction, and $\mathrm{A}$ is the absorbance of fucoxanthin solution.

\section{Conclusions}

The production of fucoxanthin from $O$. aurita is very attractive, with the maximum yield of $79.56 \mathrm{mg} \mathrm{L}^{-1}$ achieved in the bubble column photobioreactor. A comparable yield obtained in the scale-up flat plate photobioreactor confirmed the technical feasibility and scalability of $O$. aurita-based fucoxanthin production on a large-scale. Moreover, a rapid and effective procedure for 
extraction and purification fucoxanthin from the microalga was developed. The purified fucoxanthin was identified as all-trans fucoxanthin, and showed strong antioxidant properties. These results suggested that $O$. aurita may be a promising natural source of fucoxanthin for human health.

\section{Acknowledgments}

This research was financially supported by the National High Technology Research and Development Program of China (2009AA06440, 2013AA065805), the National Basic Research Program of China (2011CB2009001), the National Natural Science Foundation of China (31170337), the development Program for low carbon of Guangdong Province (2011-051) and the Fundamental Research Funds for the Central Universities (21612326).

\section{Conflict of Interest}

The authors declare no conflict of interest.

\section{References}

1. Owens, T.G.; Wold, E.R. Light-harvesting function in the diatom Phaeodactylum triconutum. Plant Physiol. 1986, 80, 732-738.

2. Abidov, M.; Ramazanov, Z.; Seifulla, R.; Grachev, S. The effects of Xanthigen ${ }^{\mathrm{TM}}$ in the weight management of obese premenopausal women with non-alcoholic fatty liver disease and normal liver fat. Diabetes Obes. Metab. 2010, 12, 72-81.

3. Woo, M.N.; Jeon, S.M.; Kim, H.J.; Lee, M.K.; Shin, S.K.; Shin, Y.C.; Park, Y.B.; Choi, M.S. Fucoxanthin supplementation improves plasma and hepatic lipid metabolism and blood glucose concentration in high-fat fed C57BL/6N mice. Chem. Biol. Interact. 2010, 186, 316-322.

4. Kawakami, T.; Tsushima, M.; Katabami, Y.; Mine, M.; Ishida, A.; Matsuno, T. Effect of $\beta$-carotene, $\beta$-echinenone, astaxanthin, fucoxanthin, vitamin $\mathrm{A}$ and vitamin $\mathrm{E}$ on the biological defense of the sea urchin Pseudocentrotus depresus. J. Exp. Mar. Biol. Ecol. 1998, 226, 165-174.

5. Kanazawa, K.; Ozaki, Y.; Hashimoto, T.; Das, S.K.; Matsushita, S.; Hirano, M.; Okada, T.; Komoto, A.; Mori, N.; Nakatsuka, M. Commercial-scale preparation of biofunctional fucoxanthin from waste parts of brown sea algae Laminalia japonica. Food Sci. Technol. Res. 2008, 14, 573-582.

6. Kim, S.M.; Shang, Y.F.; Um, B.H. A preparative method for isolation of fucoxanthin from Eisenia bicyclis by centrifugal partition chromatography. Phytochem. Anal. 2010, 22, 322-329.

7. Kim, S.M.; Jung, Y.J.; Kwon, O.N.; Cha, K.H.; Um, B.H.; Chung, D.; Pan, C.H. A potential commercial source of fucoxanthin extracted from the microalga Phaeodactylum tricornutum. Appl. Biochem. Biotechnol. 2012, 166, 1843-1855.

8. Pulz, O.; Gross, W. Valuable products from biotechnology of microalgae. Appl. Microbiol. Biotechnol. 2004, 65, 635-648.

9. Werner, D. Contributions of the Study of Diatoms to Biology. In The Biology of Diatoms; Werner, D., Ed.; Blackwell: Oxford, UK, 1977; pp. 1-3. 
10. Ibanez, E.; Herrero, M.; Mendiola, J.A.; Castro-Puyana, M. Extraction and Characterization of Bioactive Compounds with Health Benefits from Marine Resources: Macro and Micro Algae, Cyanobacteria, and Invertebrates. In Marine Bioactive Compounds: Sources, Characterization and Applications; Hayes, M., Ed.; Springer-Verlag: New York, NY, USA, 2011; pp. 55-98.

11. Drebes, D.; Schnepf, E. Gyrodinium undulans Hulburt, a marine dinoflagellate feeding on the bloom-forming diatom Odontella aurita, and on copepod and rotifer eggs. Helgol. Meeresunters. 1998, 52, 1-14.

12. De la Peña, M.R. Cell growth and nutritive value of the tropical benthic diatom, Amphora sp., at varying levels of nutrients and light intensity, and different culture locations. J. Appl. Phycol. 2007, 19, 647-655.

13. Grobbelaar, J.U. Algal Nutrition. In Handbook of Microalgal Culture: Biotechnology and Applied Phycology; Richmond, A., Ed.; Blackwell Science Ltd.: Oxford, UK, 2004; pp. 97-115.

14. $\mathrm{Hu}, \mathrm{Q}$. Environmental Effects on Cell Composition. In Handbook of Microalgal Culture: Biotechnology and Applied Phycology; Richmond, A., Ed.; Blackwell Science Ltd.: Oxford, UK, 2004; pp. 83-93.

15. Harker, M.; Tsavalos, A.J.; Young, A.J. Factors responsible for astaxanthin formation in the Chlorophyte Haematococcus pluvialis. Bioresour. Technol. 1996, 55, 207-214.

16. Ben-Amotz, A. Dunaliella $\beta$-Carotene: From Science to Commerce. In Enigmatic Microorganisms and Life in Extreme Environments; Seckbach, J., Ed.; Kluwer: Dordrecht, Netherlands, 1999; pp. 401-410.

17. Carreto, J.I.; Catoggio, J.A. Variations in pigment contents of the diatom Phaeodactylum tricornutum during growth. Mar. Biol. 1976, 36, 105-112.

18. Jin, E.; Polle, J.E.W.; Lee, H.K.; Hyum, S.M.; Chang, M. Xanthophylls in microalgae: From biosynthesis to biotechnological mass production and application. J. Microbiol. Biotechnol. 2003, $13,165-174$.

19. Ben-Amotz, A.; Shaish, A. $\beta$-Carotene Bio-synthesis. In Dunaliella: Physiology, Biochemistry and Biotechnology; Avron, M., Ben-Amotz, A., Eds.; CRC Press: Boca Raton, FL, USA, 1992; pp. 206-216.

20. Cysewski, G.R.; Todd-Lorenz, R. Industrial Production of Microalgal Cell-Mass and Secondary Products-Species of High Potential. In Handbook of Microalgal Culture: Biotechnology and Applied Phycology; Richmond, A., Ed.; Blackwell Publishing: Oxford, UK, 2004; pp. 281-288.

21. Peng, J.; Yuan, J.P.; Wu, C.F.; Wang, J.H. Fucoxanthin, a marine carotenoid present in brown seaweeds and diatoms: Metabolism and bioactivities relevant to human health. Mar. Drugs 2011, 9, 1806-1828.

22. Xiao, X.; Si, X.; Yuan, Z.; Xu, X.; Li, G. Isolation of fucoxanthin from edible brown algae by microwave-assisted extraction coupled with high-speed countercurrent chromatography. J. Sep. Sci. 2012, 35, 2313-2317.

23. Mori, K.; Ooi, T.; Hiraoka, M.; Oka, N.; Hamada, H.; Tamura, M.; Kusumi, T. Fucoxanthin and its metabolites in edible brown algae cultivated in deep seawater. Mar. Drugs 2004, 2, 63-72.

24. Jaswir, I.; Noviendri, D.; Salleh, H.M.; Miyashita, K. Fucoxanthin extractions of brown seaweeds and analysis of their lipid fraction in methanol. Food Sci. Technol. Res. 2012, 2, 251-257. 
25. Jaswir, I.; Noviendri, D.; Salleh, H.M.; Taher, M.; Miyashita, K.; Ramli, N. Analysis of fucoxanthin content and purification of all-trans-fucoxanthin from Turbinaria turbinata and Sargassum plagyophyllum by $\mathrm{SiO}_{2}$ open column chromatography and reversed phase-HPLC. J. Liq. Chromatogr. Relat. Technol. 2012, 36, 1340-1354.

26. Kim, S.M.; Kang, S.W.; Kwon, O.N.; Chung, D.; Pan, C.H. Fucoxanthin as a major carotenoid in Isochrysis aff. galbana: Characterization of extraction for commercial application. J. Korea Soc. Appl. Biol. Chem. 2012, 55, 477-483.

27. Pasquet, V.; Cherouvrier, J.R.; Farhat, F.; Thiery, V.; Piot, J.M.; Berard, J.B. Study on the microalgal pigments extraction process: Performance of microwave assisted extraction. Process Biochem. 2011, 46, 59-67.

28. Stauber, J.L.; Jeffrey, S.W. Photosynthetic pigments in fifty-one species of marine diatoms. J. Phycol. 1988, 24, 158-172.

29. Kim, K.N.; Heo, S.J.; Kang, S.M.; Ahn, G.; Jeon, Y.J. Fucoxanthin induces apoptosis in human leukemia HL-60 cells through a ROS-mediated Bcl-xL pathway. Toxicol. In Vitro 2010, 24, 1648-1654.

30. Klein, B.C.; Walter, C.; Lange, H.A.; Buchholz, R. Microalgae as natural sources for antoxidative compounds. J. Appl. Phycol. 2012, 24, 1133-1139.

31. Muller, L.; Frohlich, K.; Bohm, V. Comparative antioxidant activities of carotenoids measured by ferric reducing antioxidant power (FRAP), ABTS bleaching assay ( $\alpha$ TEAC), DPPH assay and peroxyl radical scavenging assay. Food Chem. 2011, 129, 139-148.

32. Airanthi, M.W.A.; Hosokawa, M.; Miyashita, K. Comparative antioxidant activity of edible Japanese brown seaweeds. J. Food Sci. 2011, 76, 104-111.

33. Sachindra, N.M.; Sato, E.; Maeda, H.; Hosokawa, M.; Niwano, Y.; Kohno, M.; Miyashita, K. Radical scavenging and singlet oxygen quenching activity of marine carotenoid fucoxanthin and its metabolites. J. Agric. Food Chem. 2007, 55, 8516-8522.

34. Xia, S.; Li, A.F.; Wan, L.L.; Sang, M.; Zhang, C.W. Effects of nutrients and light on the growth and biochemical compositions of a marine microalga Odontella aurita. Chin. J. Oceanol. Limnol. 2013, doi:10.1007/s00343-013-2092-4.

35. Li, Z.; Ma, X.Q.; LI, A.F.; Zhang, C.W. A novel potential source of $\beta$-carotene: Eustigmatos cf. polyphem (Eustigmatophyceae) and pilot $\beta$-carotene production in bubble column and flat panel photobioreactors. Bioresour. Technol. 2012, 117, 257-263.

36. Deng, C.; Hu, Z.; Fu, H.; Hu, M.; Xu, X.; Chen, J. Chemical analysis and antioxidant activity in vitro of a $\beta$-D-glucan isolated from Dictyophora indusiata. Int. J. Biol. Macromol. 2012, 51, $70-75$.

37. Osman, H.; Rahim, A.A.; Isa, N.M.; Bakhir, N.M. Antioxidant activity and phenolic content of Paederia foetida and Syzygium aqueum. Molecules 2009, 14, 970-978.

(C) 2013 by the authors; licensee MDPI, Basel, Switzerland. This article is an open access article distributed under the terms and conditions of the Creative Commons Attribution license (http://creativecommons.org/licenses/by/3.0/). 